\title{
Novel ABC Transporter Associated with Fluconazole Re- sistance in Aging of Cryptococcus neoformans
}

\author{
Natalia Kronbauer Oliveira ${ }^{1}$, Somanon Bhattacharya ${ }^{2}$, Rina Gambhir ${ }^{3}$, Manav Joshi ${ }^{3}$, and Bettina C. Fries ${ }^{1,2,4, *}$ \\ 1 Department of Microbiology and Immunology, Renaissance School of Medicine, Stony Brook University, \\ Stony Brook, New York, USA. \\ 2 Division of Infectious Diseases, Department of Medicine, Stony Brook University, Stony Brook, New York, \\ USA. \\ 3 Stony Brook University, Stony Brook, New York, USA. \\ 4 Veterans Administration Medical Center, Northport, New York, USA. \\ * Corresponding Author. Address of Correspondence: Bettina.Fries@stonybrookmedicine.edu
}

\begin{abstract}
Cryptococcus neoformans causes meningoencephalitis in immunocompromised individuals, which is treated with Fluconazole (FLC) monotherapy when resources are limited. This can lead to azole resistance, which can be mediated by overexpression of ABC transporters, a class of efflux pumps. ABC pump-mediated efflux of FLC is also augmented in 10-generation old C. neoformans cells. Here, we describe a new ABC transporter Afr3 (CNAG_06909), which is overexpressed in C. neoformans cells of advanced generational age, that accumulate during chronic infection. The $\Delta a f r 3$ mutant strain showed higher FLC susceptibility by FLC E-Test strip testing and also by a killing test that measured survival after $3 \mathrm{~h}$ FLC exposure. Furthermore, $\Delta a f r 3$ cells exhibited lower Rhodamine 6G efflux compared to the H99 wild type cells. Afr3 was expressed in the Saccharomyces cerevisiae $\mathrm{AD} \Delta$ strain, which lacks several drug transporters, thus reducing background transport. The AD $\Delta$ + Afr3 strain demonstrated a higher efflux with both Rhodamine 6G and Nile Red, even though the FLC MICs were not changed. Characterization of the $\triangle a f r 3$ mutant revealed unattenuated growth but a prolongation (22\%) of the replicative life span. In addition, $\Delta a f r 3$ exhibited decreased resistance to macrophage killing and attenuated virulence in the Galleria mellonella infection model. In summary, our data indicate that a novel ABC pump Afr3p, which is upregulated in C. neoformans cells of advanced age may contribute to their enhanced FLC tolerance, by promoting drug efflux. Lastly, its role in macrophage resistance may also contribute to the selection of older C. neoformans cells during chronic infection.
\end{abstract}

Keywords: drug resistance; $\mathrm{ABC}$ transporter; efflux pump; cryptococcosis; aging

\section{Introduction}

Cryptococcus neoformans is an opportunistic yeast that infects immunocompromised individuals, causing meningoencephalitis. Most recent global data estimates that Cryptococcosis affects approximately 223,100 people annually, resulting in 181,100 fatalities. Globally, this invasive fungal infection is the cause of $15 \%$ of all AIDS-related deaths [1]. The standard treatment includes amphotericin B (AMB) and 5-fluorocytosine (5-FC) as induction therapy, followed by prolonged treatment with fluconazole (FLC) for maintenance therapy [2]. In countries with limited resources, however, FLC monotherapy is used as an alternative treatment. High mortality, treatment failure, and fluconazole resistance have been described in association with FLC monotherapy [3-5].

FLC is a triazole that inhibits lanosterol $14 \alpha$-demethylase, an enzyme encoded by the ERG11 gene, which is a rate-limiting step for ergosterol biosynthesis [6,7]. Azole resistance emerges through different mechanisms. Overexpression and mutations in ERG11 decrease the susceptibility to azoles, while overexpression of efflux pumps decreases intracellular drug concentration [8-11]. Efflux of azoles is facilitated by the ATP-binding cassette $(A B C)$ transporters, a class of pumps that use ATP as an energy source to drive 
transport [12]. Three efflux pumps have been characterized in C. neoformans. Afr1 is the primary azole efflux pump and deletion of the AFR1 gene leads to lower FLC minimum inhibitory concentrations (MICs), while its overexpression causes increased FLC resistance [13]. Single deletions of another two ABC transporters, Afr2 and Mdr1, cause no change in FLC MICs. Deletion of all three transporters (Afr1, Afr2, and Mdr1) increases susceptibility to FLC compared to Afr1, suggesting that Afr1 acts as the major efflux pump, while Afr2 and Mdr1 augment Afr1 function [14]. Of note is that, when these ABC transporters were expressed in Saccharomyces cerevisiae, increased resistance to multiple azoles was observed. Furthermore, a S. cerevisiae mutant that expresses these C. neoformans transporters showed lower accumulation of radiolabeled FLC [11]. Additionally, a previous study demonstrated increased expression of these transporters in response to FLC indicating that expression of Afr1 and Afr2 was induced by FLC [14]. A search in the Cryptococcus genome database revealed a total of $41 \mathrm{ABC}$ transporters in C. neoformans. Most transporters are not characterized, and it is not understood if their expression contributes to FLC resistance in C. neoformans.

Replicative aging is a conserved trait of eukaryotic organisms and in C. neoformans it is linked closely with resilience in the host environment and increased FLC tolerance in 10 -generation-old cells $[15,16]$. Replicative aging is the result of asymmetric cell divisions. In the course of these divisions, the mother cells progressively age and accumulate ageassociated phenotypic changes. Interestingly, in S. cerevisiae ABC transporters are asymmetrically distributed in the course of replicative aging [17]. Aged mother cells exhibit increased resistance to phagocytosis and macrophage-mediated killing $[15,18]$ as well as increased tolerance to anti-fungal drugs, including FLC. A cell can undergo a finite number of divisions before senescence and the total number of divisions constitutes their replicative life span (RLS) [19], which varies greatly among clinical C. neoformans strains.

Transcriptome analysis of young and old C. neoformans cells have demonstrated differential expression of the gene CNAG_06909. This gene was identified based on homology to encode an ABC transporter. Expression was 16-fold upregulated in 10-generation old C. neoformans cells compared to young 0-3 generation-old cells. Due to similarities of the CNAG_06909 efflux pump to the previously described ABC transporters Afr1 and Afr2, we renamed the CNAG_06909 protein Afr3.

Here, we investigated the role of Afr3 in virulence and FLC resistance. We investigated virulence and FLC sensitivity of an $\triangle a f r 3$ mutant strain and measured efflux function. To exclude compensation by other efflux pumps we expressed Afr3p in the $S$. cerevisiae strain $(\mathrm{AD} \Delta)$, which lacks other $\mathrm{ABC}$ transporters [6] [11]. The present study demonstrates that Afr3 is an ABC transporter that is upregulated in old cells where it effluxes FLC, which may contribute to the age-dependent FLC tolerance in C. neoformans.

\section{Materials and Methods}

\subsection{Strains and Media}

C. neoformans strains $\mathrm{H} 99$ and $\Delta a f r 3, \Delta a f r 1$, and $\Delta a f r 2$ mutants were cultured in synthetic media (SM; $1.7 \mathrm{~g}$ yeast nitrogen base without amino acids (BD), $1 \mathrm{~g}$ drop out mix (USBiological Life Sciences, Salem, MA, USA), $4 \mathrm{~mL}$ ethanol, $5 \mathrm{~g}\left(\mathrm{NH}_{4}\right)_{2} \mathrm{SO}_{4}, 3.3 \mathrm{~g} \mathrm{NaCl}, 20$ $\mathrm{g}$ glucose). Calorie restriction synthetic media was prepared as follows (CR, $1.7 \mathrm{~g}$ yeast nitrogen base without amino acids (BD), $1 \mathrm{~g}$ drop out mix (USBiological Life Sciences,

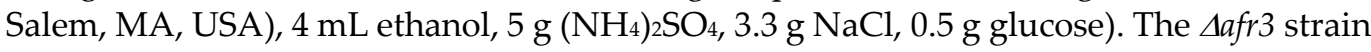
was derived from the Madhani knockout collection, which is managed by the Fungal Genetics Stock Center. The $\Delta a f r 1$ and $\Delta a f r 2$ strains were gifted by Dr. Kwon-Chung Lab [14]. The mutant $S$. cerevisiae strains were cultured in complete supplement medium without uracil (CSM -ura (MP Bio); 20 g galactose, $1.7 \mathrm{~g} \mathrm{YNB}, 5 \mathrm{~g}\left(\mathrm{NH}_{4}\right)_{2} \mathrm{SO}_{4}, 0.77 \mathrm{~g}$ CSM -ura). S. cerevisiae AD $\Delta$ strain, in which several ABC transporters and the URA3 locus were deleted, was previously described [20]. AD $\Delta$ strain and pYES2 plasmid were obtained as a gift from Dr. Theodore C. White at the University of Missouri, Kansas City. 
All strains used in this study are maintained as $30 \%$ glycerol stocks and stored at $-80^{\circ} \mathrm{C}$ for future use.

\subsection{Construction of S. cerevisiae Strain Expressing Efflux Pumps}

First, RNA was extracted from exponentially growing H99 cells using RNAeasy Plus kit (Qiagen) following manufacturer's guidelines. Next, 250 ng of RNA was converted to cDNA using Verso cDNA Kit (Thermo Scientific) in a $20 \mu \mathrm{l}$ reaction. AFR3 was amplified from the cDNA using oligos that partially overlapped with the pYES2 plasmid (Table S1), using a thermocycler (Biorad). The forward oligonucleotide was designed to contain 40bp homologous sequence of GAL1 promoter (primer AFR3 + pGAL1) while the reverse oligonucleotide was designed to contain 40bp homologous sequence of CYC1 terminator (primer AFR3 + CYC1 tt). The plasmid contains an URA3 auxotrophic selection marker. pYES2 was first digested with HindIII and then transformed into AD $\Delta$ strain with the addition of the AFR3 cassette, as previously described [21]. The AD $\Delta$ strain lacks seven ABC transporters ( $\Delta y$ or 1, $\Delta s n q 2, \Delta p d r 10, \Delta p d r 11, \Delta y c f 1, \Delta p d r 5$, and $\Delta p d r 15$ ), a transcription factor $(\Delta p d r 3)$, and the URA3 gene ( $\triangle u r a 3)$. Homologous recombination was used to integrate the AFR3 cassette into pYES2. Undigested plasmid pYES2 without the cassette was transformed into AD $\Delta$ for positive control. Transformants were selected on CSM ura agar plates after incubation at $37^{\circ} \mathrm{C}$ for 4 days. To screen for proper integration, $12-15$ colonies were selected and replicated into fresh selective plates three consecutive times. Transformants were confirmed by plasmid extraction with QIAprep Spin Miniprep Kit (Qiagen) and PCR for AFR3 cassette using oligos that amplified the whole gene sequence (primers AFR3 F and AFR3 R) (Table S1, Figure S1A). Expression was measured using the RNAeasy Plus kit (Qiagen) to extract RNA from AD $\Delta$ and AD $\Delta+$ Afr3 and RNA was converted to cDNA using Verso cDNA Kit (Thermo Scientific). cDNA was diluted 1:5 and analyzed with qPCR analysis (Roche) using Power Sybr Green Master Mix (Applied Biosystems) following manufacture's protocols (primers qPCR Afr3 F and qPCR Afr3 R, Table S1). House-keeping gene encoding $\beta$-actin (primers Sc ACT1 F and Sc ACT1 R) was used as an internal control (Table S1, Figure S1B). Furthermore, samples were sent for sequencing to ensure that the AFR3 sequence did not undergo mutations.

\subsection{Isolation of Old C. neoformans Strains}

Isolation of 10-generation-old C. neoformans cells was performed following previously published protocol [22]. Briefly, the cells from the strains H99, $\Delta$ afr 1, and $\Delta a f r 3$ were incubated overnight at $37^{\circ} \mathrm{C}$ in SM media. The next day, the overnight cultures were washed three times with 1X PBS and were diluted 1:50 times. The diluted cells were then exponentially grown for 6-8 hours. After the exponential growth, the cells were washed three times with $1 \mathrm{X}$ PBS and counted with a hemocytometer. $10^{8}$ cells from each strain were then labeled with $8 \mathrm{mg} / \mathrm{ml}$ sulfosuccinimidyl-6-[biotin-amido] hexanoate (SulfoNHS-LC-LC-Biotin, 21338, ThermoFisher Scientific) for 30 minutes at room temperature (RT). The labeled cells were then washed three times in 1X PBS and the washed cells were grown in fresh SM media for 5 generations (12-15 h). After 5 generation cell growth for each strain, the cells were washed three times with 1X PBS and labeled with $100 \mu$ of streptavidin microbeads (130-048-101, Miltenyi Biotec) at a final concentration of $10^{8}$ cells $/ \mathrm{mL}$. The streptavidin labeling was done for 15 minutes at $4^{\circ} \mathrm{C}$. The labeled cells were washed three times with 1X PBS to remove any unbound streptavidin. The biotinstreptavidin labeled 5 generation cells were then separated by passing the mixed population through AutoMACS® Pro Separator (Miltenyi Biotec). The positively labeled cells were retained in the column attached to the magnet in the pro-separator machine. These cells were retrieved once the magnetic field was removed. These 5 generation old cells were then further grown in fresh SM media for another 5 generations $(12-15 \mathrm{~h})$. The grown cells were again washed and passed through AutoMACS® Pro Separator (Miltenyi Biotec) to retrieve the 10 generation old cells. The purity of the population was verified by 
microscopy. As a control, the young generation cells, washed-off from the magnetic columns, from the second separation were used.

\subsection{Antifungal Susceptibility Testing}

The Minimum Inhibitory Concentration (MIC) was determined as per a previously published protocol [23]. Briefly, the C. neoformans and S. cerevisiae strains were cultured overnight at $37^{\circ} \mathrm{C}$, and cells were adjusted to $10^{5}$ cells/well for $\mathrm{C}$. neoformans and $5 \times 10^{5}$ cells/well for $S$. cerevisiae. FLC was two-fold serially diluted in a flat-bottom 96-well plate (Costar) with a starting FLC concentration of $64 \mu \mathrm{g} / \mathrm{mL}$. The plates were incubated at 37 ${ }^{\circ} \mathrm{C}$ for 4 days and the OD600 was measured (SpectraMax i3x, Molecular Devices). A row with no drugs was used as a growth control while a row with no cells was used as contamination control in the MIC assay. MICs were defined as the minimum drug concentration that inhibits $80 \%$ of the cell growth $\left(\mathrm{MIC}_{80}\right)$ or $50 \%$ of the cell growth (MIC50). The assay was performed in triplicate. For analysis of MICs under CR, the same conditions were performed, in which the cells were cultured in synthetic media with $0.05 \%$ glucose. FLC E-Test was also performed to determine FLC susceptibility. $10^{6}$ cells from both $\mathrm{H} 99$ and $\triangle a f r 3$ mutant strains were plated in YPD media containing FLC E-Test Strip (Biomerieux) and incubated at $37^{\circ} \mathrm{C}$ for 4 days.

FLC Killing assay was performed using previously published protocol [24]. Briefly, the young and the 10 generation-old cells were isolated as described above. After isolation, the cells were washed three times with $1 \mathrm{X}$ PBS and $10^{4}$ cells per well were seeded in 96 well plates (Costar) containing FLC at concentrations of 50, 25, 12.5, 6.25, and 3.125 $\mu \mathrm{g} / \mathrm{mL}$. Cells were also plated in wells containing no drug. Next, the 96 well plates were incubated at $37^{\circ} \mathrm{C}$ for $3 \mathrm{~h}$ without shaking. After incubation, the cells were diluted 50 times and plated in YPD agar plates. The agar plates were incubated for $48 \mathrm{~h}$ and colonyforming units (CFUs) were counted. Percent killing was analyzed by the following formula:

$$
\% \text { killing }=\frac{\text { CFUs in no drug well-CFUs in drug well }}{\text { CFUs in no drug well }} \times 100
$$

The assays were done in triplicate. All YPD plates and drug concentrations were made fresh on the day of the experiment.

\subsection{Rhodamine 6G Efflux Assay}

Rhodamine 6G assay was performed as previously described [25]. Briefly, 5x107 C. neoformans and $2 \times 10^{7}$ S. cerevisiae cells were starved for $2 \mathrm{~h}$ in phosphate buffer saline (PBS; $\mathrm{pH}$ 7.4) buffer at room temperature. Rhodamine 6G (Sigma) was added to a final concentration of $10 \mu \mathrm{M}$ and the cells were incubated at $37{ }^{\circ} \mathrm{C}$ for $30 \mathrm{~min}$. Following the incubation, cells were washed $3 x$ in PBS, and efflux was initiated by the addition of $2 \%$ glucose. Samples were collected at $0 \mathrm{~min}, 10 \mathrm{~min}, 20 \mathrm{~min}$, and $30 \mathrm{~min}$ timepoints, and fluorescence of the supernatants was measured at $525 \mathrm{~nm}$ excitation and $555 \mathrm{~nm}$ emission wavelengths. The experiment was performed independently on three different days.

\subsection{Nile Red Assay}

Briefly, the cells from AD $\Delta$ and AD $\Delta+$ Afr3 were grown in the CSM-ura media. After growth $10^{7}$ cells were used for the Nile Red assay. First, the cells were washed in PBS three times and then starved for 2 hours in PBS to get rid of any residual glucose. After starvation, Nile red was added to the cells at a final concentration of $7 \mu \mathrm{M}$. The efflux was initiated after the addition of $2 \%$ glucose to the starved cells. Accumulation of Nile Red was measured using fluorescence plate reader (SpectraMax I3) at 0 mins and 30 mins using excitation wavelength of $553 \mathrm{~nm}$ and emission of $636 \mathrm{~nm}$. Accumulation was calculated in percentage. More accumulation of the dye at the end of $30 \mathrm{mins}$ period signifies lesser efflux. The assay was done in triplicate. 


\subsection{Replicative Life Span (RLS)}

The RLS was determined by microdissection as outlined elsewhere [22]. Briefly, 2030 naïve cells were isolated and arrayed in a straight line in SM plates. Every time a mother cell budded (1-2 h), the daughter cell was separated using a $25 \mu \mathrm{m}$ needle (CoraStyles) under a tetrad dissection Axioscope A1 microscope (Zeiss) at 250X magnification. After each budding event, the plates were incubated at $37^{\circ} \mathrm{C}$. The RLS was determined by the number of times the mother cell buds before dying ( $24 \mathrm{~h}$ without a budding event).

\subsection{Galleria mellonella infection}

Galleria mellonella infection was performed as previously described [26]. G. mellonella larvae were obtained from Vanderhorst Wholesale Inc., St. Mary's, OH, United States. C. neoformans cells were washed and diluted to $10^{6} \mathrm{cell} / \mathrm{s} / \mathrm{mL}$ in PBS. The worms were injected with $10 \mu \mathrm{L}$ of the cell suspension and PBS was used as a negative control. Twenty worms were used for each group. Survival of the worms was observed for a week. Retention of C. neoformans cells in the hemolymph of Galleria larvae was analyzed as an independent experiment. The worms were injected with $5 \times 10^{4} \mathrm{C}$. neoformans cells and the hemolymph was extracted after $24 \mathrm{~h}$. The samples were plated in YPD agar plates and the CFU was counted after $48 \mathrm{~h}$ incubation at $37^{\circ} \mathrm{C}$.

\subsection{Growth Curve}

Growth curves for H99, $\Delta a f r 3, \Delta a f r 1$, and $\Delta a f r 2$ strains were performed in 96-well flatbottom plates, in which $0.1 \mathrm{OD}_{600}$ cells were used in triplicate for each strain. The growth curve was carried on for $72 \mathrm{~h}$ in a SpectraMax i3x (Molecular Devices) at $37^{\circ} \mathrm{C}$ with shaking.

\subsection{Expression Analysis}

Strains were grown overnight in their respective media. For pump compensation analysis, H99, $\triangle a f r 3$, and $\triangle a f r 1$ were grown overnight in SM media. AFR3 expression in low glucose was performed in $\mathrm{H} 99$ cells grown overnight in SM and calorie restriction low glucose media. Finally, for pump analysis under FLC treatment, we grew H99 overnight in SM media, followed by a $2 \mathrm{~h}$ treatment under $32 \mu \mathrm{g} / \mathrm{mL}$ of FLC of $10^{7}$ cells. For 10-generation $C$. neoformans quantification, we isolated young and old H99 cells, where we quantified AFR1, AFR2, and MDR1 expression. RNA was extracted using RNAeasy Plus kit (Qiagen) following manufacturer's guidelines. Next, RNA was quantified using a Biospectrophotometer (Eppendorf), in which an absorbance ratio (A260/A280) of 2.0 or higher was considered good quality RNA. 250 ng of RNA was converted to cDNA using Verso cDNA Kit (Thermo Scientific) in a $20 \mu$ reaction. cDNA was diluted 1:5 with RNase/DNase-free water (HyClone Laboratories). qPCR expression analysis (Roche Life Science) was performed using Power Sybr Green Master Mix (Applied Biosystems) following the manufacturer's protocol. Oligonucleotides used to analyze gene expression of $A F R 1$ and $A F R 3$ are described in Table S1. House-keeping gene $A C T 1$ was used as an internal control. Data was normalized and calculated using the $2-$ ${ }^{\Delta \Delta \mathrm{Ct}}$ method as previously described [27].

\subsection{Macrophage- mediated Killing Assay}

Macrophage-mediated killing assay was performed according to previously published protocol [18]. Briefly, 5x104 cells of J774A.1 murine macrophage cell line were seeded in 96 well plates (Costar) in DMEM (Gibco) media containing 10\% Fetal Bovine Serum (FBS), 10\% NCTC (Gibco), 1\% non-essential amino acids, and 1\% penicillinstreptomycin. The 96 well plates were incubated at $37^{\circ} \mathrm{C}$ with $5 \% \mathrm{CO}_{2}$ for $24 \mathrm{~h}$. After 
incubation, the cells were activated with LPS and IFN $\gamma$ as described previously. In a separate tube, young and old C. neoformans cells were opsonized for 30 mins at $37^{\circ} \mathrm{C}$ with $18 \mathrm{~b} 7$ antibody. The opsonized C. neoformans cells were then added to the 96 well plates containing the activated macrophages at an MOI of 1:1. The plates were incubated for $1 \mathrm{~h}$ at $37{ }^{\circ} \mathrm{C}$ with $5 \% \mathrm{CO}_{2}$ to allow phagocytosis. After phagocytosis, all wells were washed three times with 1X PBS to remove the non-phagocytosed C. neoformans cells. After washing, half of the wells of macrophages were lysed using sterile water, and $C$. neoformans cells were plated in YPD to determine the number of C. neoformans cells phagocytosed (time 0). Next, to the other half of macrophage-containing wells, fresh DMEM media was added. The macrophages along with the phagocytosed $C$. neoformans cells were incubated for another $1 \mathrm{~h}$ at $37{ }^{\circ} \mathrm{C}$ with $5 \% \mathrm{CO}_{2}$. This was done to analyze macrophage-mediated killing of young and old C. neoformans cells. After $1 \mathrm{~h}$ of killing, the wells were washed three times with 1X PBS. The macrophages were then lysed and the surviving $C$. neoformans cells were plated in YPD agar plates. YPD plates were then incubated at $37^{\circ} \mathrm{C}$ for $48 \mathrm{~h}$ and CFUs were counted. The assay was performed in triplicate. Macrophage-mediated killing was calculated as follows:

$\%$ macrophage-mediated killing $=\frac{\text { CFU post phagocytosis at time } 0-C F U \text { after } 1 \mathrm{~h} \text { killing }}{\text { CFU post phagocytosis at time } 0} \times 100$

\subsection{Statistics}

Statistical analyses were performed using GraphPad Prism 9.0. The specific analyses are described in the figure legends. The coefficient of variation $(\mathrm{CV})$ is calculated by dividing de standard deviation (SD) by the mean of the strain $(\mathrm{CV} \%=\mathrm{SD} /$ mean $\times 100)$.

\section{Results}

\subsection{Afr3 is Similar to Other ABC Transporters}

Based on amino acid sequence, CNAG_06909 exhibits 29\% and 26\% homology to Afr1 (CNAG_00730) and Afr2 (CNAG_00869) respectively, with a high query coverage of above $85 \%$ (Table 1). Protein sequence similarity between Afr1 and Afr2 is $38 \%$, which is comparable to the similarity of CNAG_06909 transporter with either Afr1 or Afr2. Furthermore, CNAG_06909 contains an ABC transporter domain, while Afr1 contains two domains. Afr2, similarly to Afr1, also contains two ABC transporter domains. Performing an alignment and analysis employing NCBI Blast Tool exhibits high similarity between the ABC transporter domain of Afr3 (CnAFR3) and the two domains of Afr1 (CNAFR1.1 and CnAFR $1.2 ; 46 \%$ positives, $25 \%$ identities, and $53 \%$ positives, $35 \%$ identities, respectively) (Figure 1). Based on the similarity with Afr1 and Afr2, and the below characterized functional overlap we have renamed the CNAG_06909 gene AFR3 and the protein Afr3.

\subsection{The Afr3 Efflux Pump is Important for C. neoformans FLC tolerance}

Given the known role of $\mathrm{ABC}$ transporters in mediating azole resistance in fungal cells, we assessed FLC susceptibility in $\mathrm{H} 99$ and $\triangle a f r 3$ with standard methods with slight modifications. First, we performed a FLC E-Test strip analysis on SM media plates, in

Table 1. Similar Proteins to Afr3 Across Different Fungal Species

\begin{tabular}{|c|c|c|c|c|c|c|c|}
\hline Description & $\begin{array}{l}\text { Max } \\
\text { Score }\end{array}$ & $\begin{array}{l}\text { Total } \\
\text { Score }\end{array}$ & $\begin{array}{l}\text { Query } \\
\text { Cover }\end{array}$ & $\begin{array}{c}\mathrm{E} \\
\text { value }\end{array}$ & $\begin{array}{c}\% \\
\text { Identity }\end{array}$ & $\begin{array}{c}\text { Accession } \\
\text { length }\end{array}$ & $\begin{array}{l}\text { Accession } \\
\text { Code }\end{array}$ \\
\hline $\begin{array}{l}\text { ATP-binding cassette transporter [Cryptococcus } \\
\text { neoformans var. grubii H99] }\end{array}$ & 205 & 302 & $86 \%$ & $3 e-55$ & $29.29 \%$ & 1543 & CNAG_00730 \\
\hline
\end{tabular}




\begin{tabular}{|c|c|c|c|c|c|c|c|}
\hline $\begin{array}{l}\text { ABC transporter [Cryptococcus neoformans var. } \\
\text { grubii H99] }\end{array}$ & 199 & 340 & $88 \%$ & $3 e-53$ & $31 \%$ & 1462 & CNAG_07799 \\
\hline $\begin{array}{l}\text { ATP-dependent permease [Cryptococcus neofor- } \\
\text { mans var. grubii H99] }\end{array}$ & 179 & 234 & $77 \%$ & $1 \mathrm{e}-44$ & $36.96 \%$ & 1173 & CNAG_06533 \\
\hline $\begin{array}{l}\text { ABC transporter family protein [Cryptococcus } \\
\text { neoformans var. grubii H99] }\end{array}$ & 170 & 313 & $61 \%$ & $9 \mathrm{e}-44$ & $30.99 \%$ & 1241 & CNAG_05470 \\
\hline $\begin{array}{l}\text { ABC transporter PMR5 [Cryptococcus neoformans } \\
\text { var. grubii H99] }\end{array}$ & 165 & 315 & $87 \%$ & $5 e-42$ & $25.05 \%$ & 1421 & CNAG_06348 \\
\hline $\begin{array}{l}\text { ATP-binding cassette transporter [Cryptococcus } \\
\text { neoformans var. grubii H99] }\end{array}$ & 144 & 271 & $90 \%$ & $1 \mathrm{e}-39$ & $26.06 \%$ & 1529 & CNAG_00869 \\
\hline $\begin{array}{l}\mathrm{ABC} \text { transporter, putative [Cryptococcus } \\
\text { neoformans var. neoformans JEC21] }\end{array}$ & 204 & 343 & $86 \%$ & $3 e-56$ & $30.16 \%$ & 1463 & CNL06490 \\
\hline $\begin{array}{l}\text { ABC transporter [Cryptococcus gattii VGIV } \\
\text { IND107] }\end{array}$ & 1167 & 1167 & $100 \%$ & 0.0 & $93.45 \%$ & 625 & KIR83217.1 \\
\hline $\begin{array}{l}\text { related to ATP-binding cassette protein (ABC) } \\
\text { transporter [Ustilago trichophora] }\end{array}$ & 208 & 413 & $85 \%$ & $3 e-58$ & $41.35 \%$ & 669 & SPO26649.1 \\
\hline abc transporter [Lasallia pustulata] & 671 & 671 & $96 \%$ & 0.0 & $54.27 \%$ & 637 & KAA6412381.1 \\
\hline $\begin{array}{l}\text { hypothetical protein EHS25_004009 [Saitozyma } \\
\text { podzolica] }\end{array}$ & 910 & 910 & $95 \%$ & 0.0 & $73.22 \%$ & 1711 & RSH94206.1 \\
\hline
\end{tabular}

A

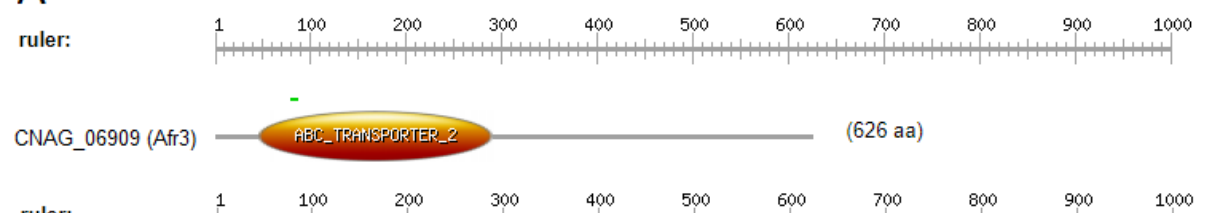

ruler:

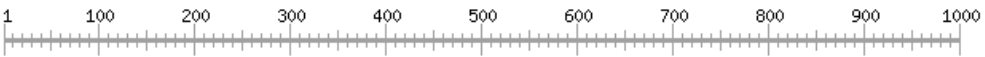

CNAG_00730 (Afr1)

B

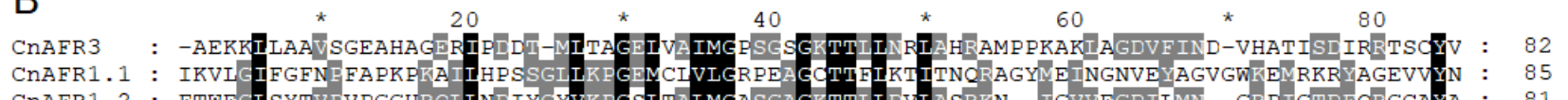

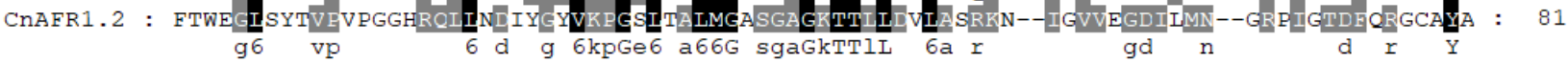
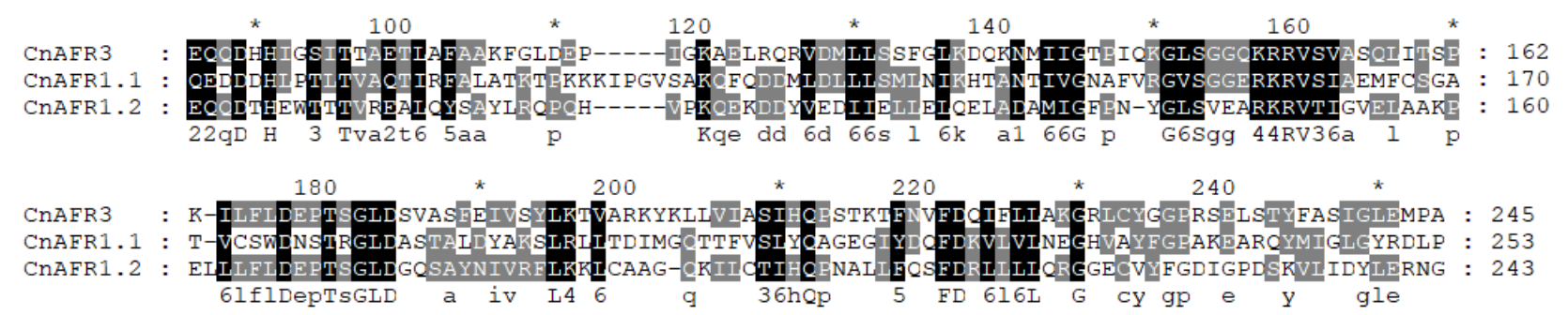

Figure 1. Afr3 (CNAG_06909) Has Similar Motifs to Afr1 (CNAG_00730). (A) Afr3 possesses one ABC transporter motif, while Afr1 has two. The search was conducted using Prosite (https://prosite.expasy.org/scanprosite/); (B) Alignment analysis between the ABC transporter domain of Afr3 (CnAFR3) and the two domains of Afr1 (CnAFR1.1 and CnAFR1.2) was performed with ClustalW, in the BioEdit program. The figure was generated using GeneDoc. Sequences in black are highly conserved.

which $\Delta$ afr3 displayed a lower MIC than $\mathrm{H} 99(0.75 \mu \mathrm{g} / \mathrm{mL}$ vs. $4 \mu \mathrm{g} / \mathrm{mL})$ (Figure 2A). It is noteworthy, that the $\Delta$ afr3 mutant lacked heteroresistance whereas individual colonies grew at higher MIC in the wild-type $\mathrm{H} 99$ consistent with heteroresistance. Next, we explored whether AFR3 was overexpressed during FLC treatment. After a $2 \mathrm{~h}$ FLC treatment, $A F R 3$ did not show an increase in expression when compared to $\mathrm{H} 99$ cells without treatment (Figure 2B).

Given augmented ABC transporter-mediated efflux of FLC is the main mechanism of how ABC pumps mediate FLC resistance in C. neoformans, we explored efflux pump 
activity of $\Delta a f r 3$. The fluorescent dye Rhodamine 6G was added to $C$. neoformans cells and the cellular efflux was initiated by the addition of glucose, followed by fluorescence measurement in the supernatant. These data demonstrated that $\Delta a f r 3$ exhibited lower efflux than wild-type in all three time points $(10,20$, and $30 \mathrm{~min} ; \mathrm{p}<0.001)$ (Figure 2C), indicating that Afr3 is a relevant efflux pump.

FLC MIC analysis under low glucose media ( $0.05 \%$ glucose) was performed because such conditions are encountered by $C$. neoformans in vivo. These data showed that both strains increased FLC tolerance under low glucose, with no difference between H99 and $\triangle a f r 3$ strains, indicating that Afr3 is not responsible for the increase in FLC tolerance observed under low glucose conditions (Figure 2D). Of note, the FLC MIC 80 was the same for $\mathrm{H} 99$ and $\triangle a f r 3$ in a broth microdilution assay. This data was further supported by expression analysis of AFR3 under low glucose, in which the AFR3 levels were not significantly increased (Figure 2E). Possible pump compensation between Afr3 and Afr1 was also studied. AFR1 expression was measured in $\triangle a f r 3$ strain, while AFR3 expression was measured in $\triangle a f r 1$ strain to seek for upregulation. Upregulation of $A F R 1$ in a $\triangle a f r 3$ strain would indicate that there is increased production of Afr1 to compensate for the lack of Afr3, and vice-versa. No upregulation was observed in this analysis, which indicates no compensation between Afr1 and Afr3 (Figure S2).

Given that Afr3, as well as Afr1 and Afr2, are overexpressed in 10-generation old cells (Table 2), we assessed the contribution of Afr3 to age-associated FLC tolerance with established high dose FLC killing assays, since growth-based assays can only assess FLC MICs of young $C$. neoformans cells. Killing of young and old C. neoformans cells was assessed after $3 \mathrm{~h}$ exposure to high doses of FLC ranging from $50 \mu \mathrm{g} / \mathrm{mL}$ to $3.125 \mu \mathrm{g} / \mathrm{mL}$. As expected, these assays demonstrated that the $\Delta a f r 3$ mutant was killed more efficiently over a range of FLC doses when compared to the wild-type H99 (4afr3 Y vs H99 Y, FLC 50, 25, $12.5 \mu \mathrm{g} / \mathrm{mL}$ : 80 vs. 25 \%; FLC $6.25 \mu \mathrm{g} / \mathrm{mL}$ : 48 vs 7 \%; FLC $3.125 \mu \mathrm{g} / \mathrm{mL}: 60$ vs 5 \%; \#\# p < 0.001) (Figure $2 F$ ). Older C. neoformans cells showed higher tolerance to FLC killing than younger C. neoformans cells for most FLC concentrations for both H99 (H99 O vs H99 Y; FLC $50 \mu \mathrm{g} / \mathrm{mL}$ : 13 vs $25 \%$, p < 0.05; FLC $25 \mu \mathrm{g} / \mathrm{mL}: \sim 0$ vs $23 \%$, p < 0.01; and FLC 12.5

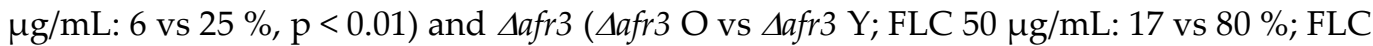
$25 \mu \mathrm{g} / \mathrm{mL}$ : $35 \mathrm{vs} 80 \%$; and FLC $12.5 \mu \mathrm{g} / \mathrm{mL}$ : 37 vs $79 \%$; p 0.01). The H99 wild-type data corroborates data previously published for the RC2 strain [19]. The percentage FLC killing of older $\Delta a f r 3$ cells, however, was higher than the killing of 10- generation H99 cells ( $\triangle a f r 3$ O vs H99 O; FLC $25 \mu \mathrm{g} / \mathrm{mL}$ : 35 vs 0 \%, FLC $12.5 \mu \mathrm{g} / \mathrm{mL}: 37$ vs 6 \%; and FLC $6.25 \mu \mathrm{g} / \mathrm{mL}$ : 38 vs $\sim 0 \%$; $\$<0.05)$, indicating that the presence of the Afr3 efflux pump may contribute to age-associated FLC tolerance, but is not the only factor.

Table 2. Efflux Pumps Expression in 10-generation Cells

\begin{tabular}{llll}
\hline Strain & qPCR Fold-change & P value & Significant? \\
\hline Afr1 & 28.26 & 0.0415 & Yes \\
Afr2 & 5.16 & 0.0026 & Yes \\
Afr3 & $16.06^{*}$ & 0.0017 & Yes \\
Mdr1 & 4.36 & 0.0108 & Yes \\
\hline
\end{tabular}

* [15] 
A

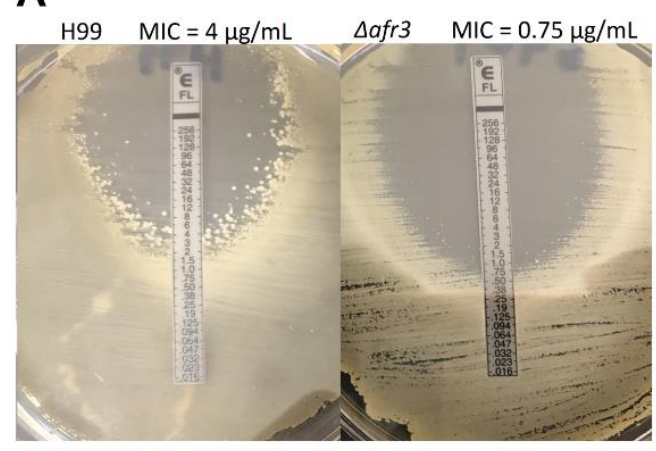

D

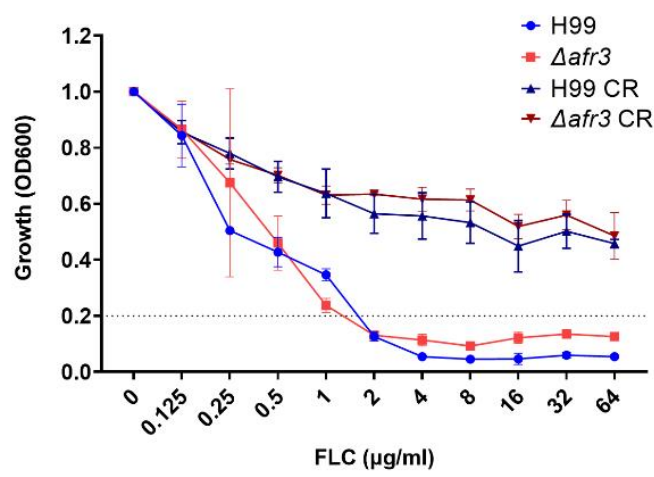

B

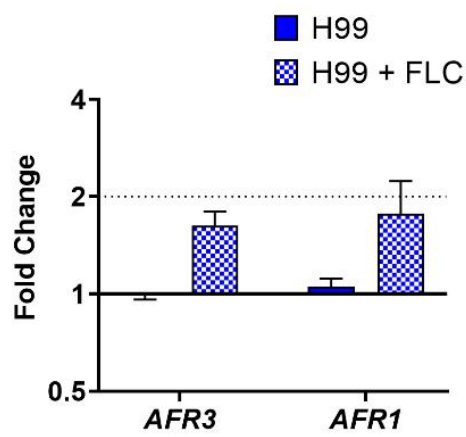

C

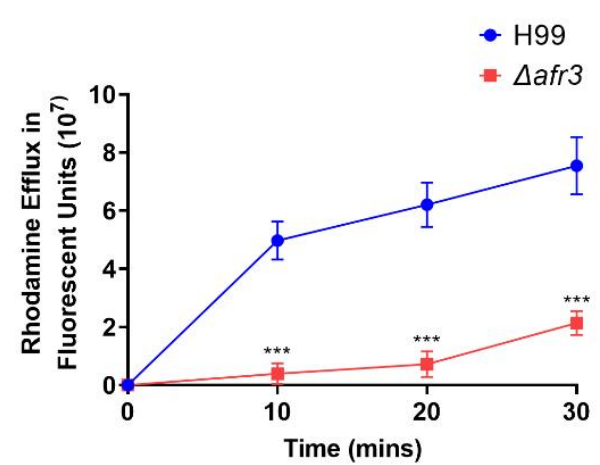

$\mathbf{F}$

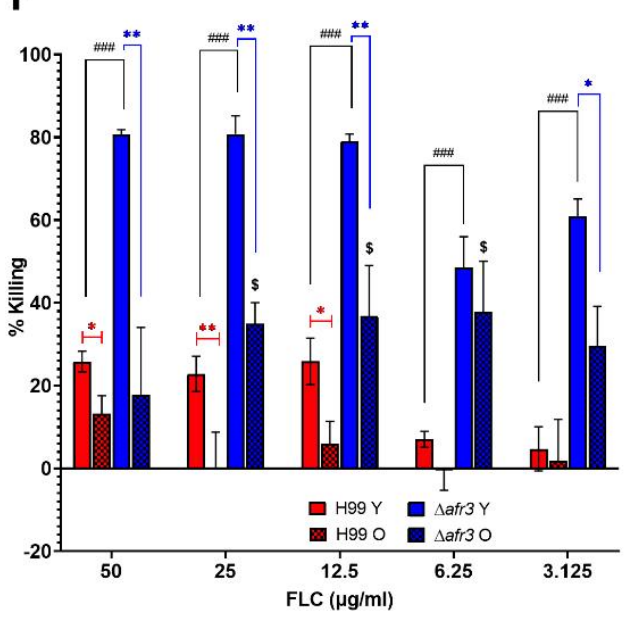

Figure 2. Afr3 is an Important Pump for Drug Resistance. (A) C. neoformans Aafr3 is more sensitive to FLC than H99 in an FLC E-Test in a YPD plate; (B) H99 cells that underwent FLC treatment with $32 \mu \mathrm{g} / \mathrm{mL}$ for $2 \mathrm{~h}$ (checkered blue/white bar) do not increase expression of $A F R 3$ and AFR1 compared to H99 wild-type (blue bar); (C) $\triangle a f r 3$ (red line) decreases efflux compared to H99 (blue line) in a Rhodamine 6G assay. Statistical analysis was performed with multiple unpaired Student's t-test, ${ }^{* * *} \mathrm{p}<0.001$; (D) FLC tolerance observed under CR conditions (SM 0.05\% glucose) (H99 CR: dark blue line, $\Delta a f r 3$ CR: dark red line) is independent of Afr3 presence, as shown by the susceptibility under normal conditions (SM 2\% glucose) (H99: blue line, $\triangle a f r 3$ : red line); (E) Expression of AFR3 is not increased under CR conditions (checkered blue bar) when compared to normal glucose conditions (blue bar); (F) The $\Delta a f r 3$ young cells ( $\triangle a f r 3 \mathrm{Y}$, blue bar) are more susceptible to FLC killing than H99 young cells (H99 Y, red bar. Furthermore, Aafr3 old cells (4afr3 O, checkered blue bar) lose FLC killing tolerance when compared to H99 old cells (H99 O, checkered red bar). Statistical analysis was performed with multiple unpaired Student's t-test, ${ }^{*} \mathrm{p}<0.05,{ }^{* *} \mathrm{p}<0.01$, \#\#\# $\mathrm{p}<0.001$, and $\$ \mathrm{p}<0.05$; Error bars represent the standard deviation between biological triplicates.

\subsection{S. cerevisiae Expression of Afr3 Increases Drug Efflux}

To exclude compensation by other ABC transporters when the Afr3 pump is deleted, we expressed Afr3p in the S. cerevisiae AD $\Delta$ strain, which lacks all seven of the main ABC transporters, thus reducing background transport. We expressed Afr3 in pYES2 plasmid under a GAL1 promoter (Fig 3A) that permits the expression of Afr3 only in presence of galactose. FLC MICs for AD $\Delta$ control and AD $\Delta$ expressing Afr3 (AD $\Delta+$ Afr3) showed no difference between the strains for $\mathrm{MIC}_{80}$ (Figure $3 \mathrm{~B}$ ). This might be due to the longer period of incubation used for the assay, which could lead to a decrease in protein activity.

Next, we sought to evaluate the efflux activity of the $S$. cerevisiae strains. Rhodamine 6G efflux was increased in the AD $\Delta+$ Afr3 strain when compared to AD $\Delta$ after 20 min (p $<0.01)$ and $30 \mathrm{~min}(\mathrm{p}<0.0001)$ (Figure $3 \mathrm{C})$. We also performed a Nile Red Assay in which cells were incubated with Nile Red and glucose was added to initiate transport. The percentage of Nile Red accumulation inside the fungal cells was quantified by measuring the fluorescence after $30 \mathrm{~min}$. AD $\Delta+$ Afr3 mutant exhibited decreased intracellular Nile Red 
accumulation when compared to the AD $\Delta$ strain $(p<0.01)$ (Figure 3D). These results confirmed Afr3 efflux activity and showed that this pump exhibits efflux pump activity independent from other ABC pumps.

A
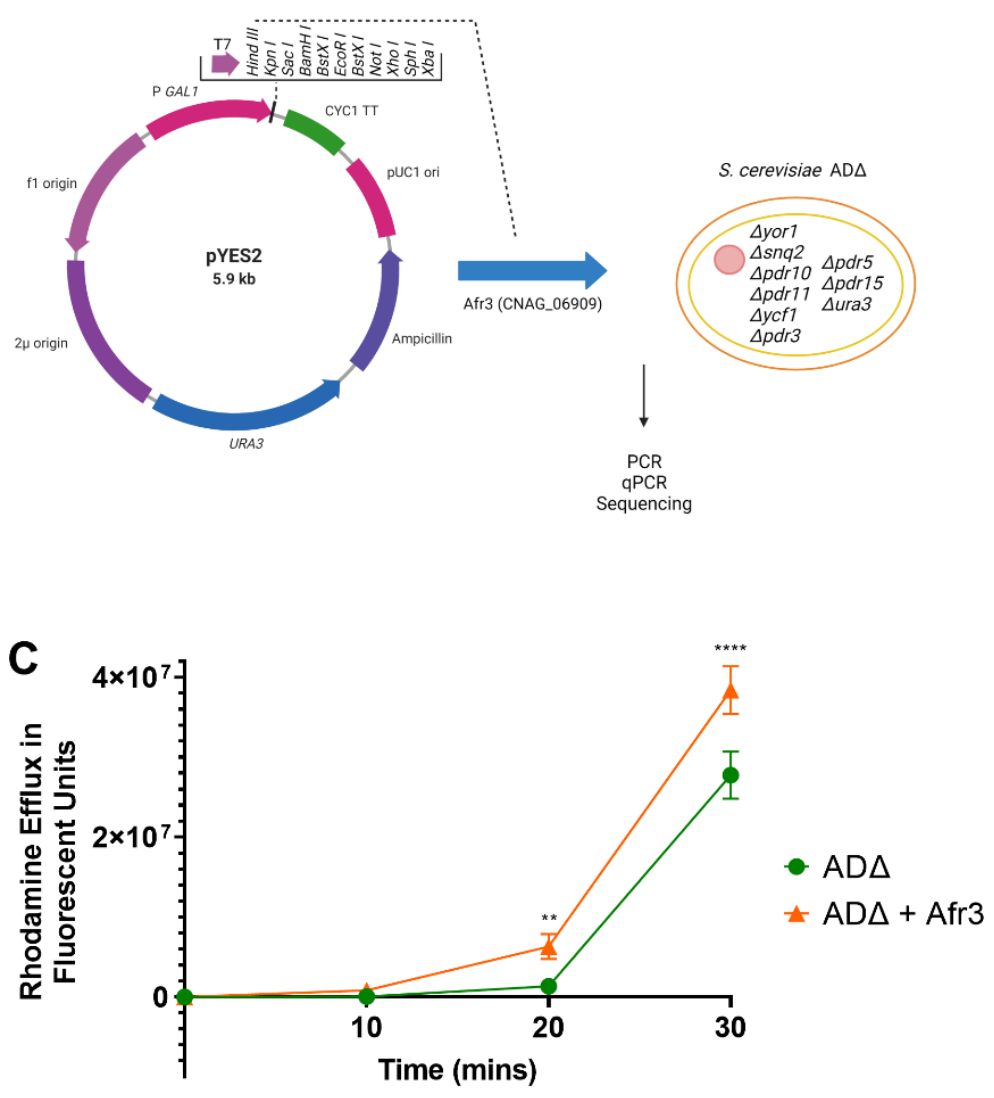

B

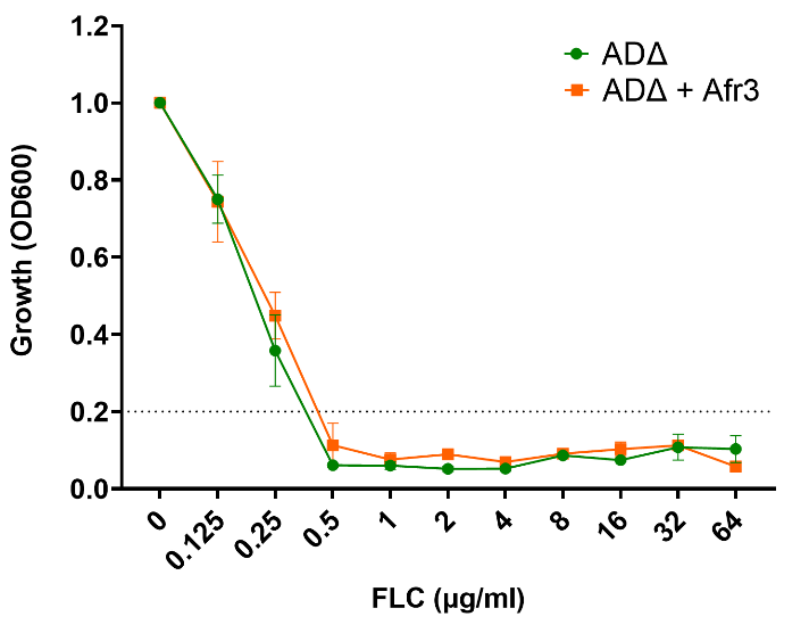

D

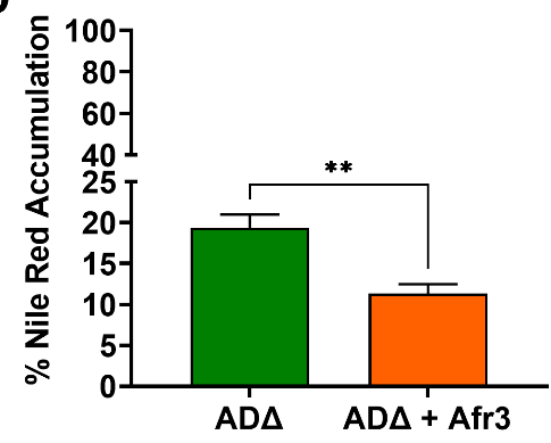

Figure 3. Afr3 Expression in Saccharomyces cerevisiae Increases Efflux. (A) Schematic diagram of Afr3 expression in S. cerevisiae AD $\Delta$ strain. The pYES2 plasmid contains a URA3 auxotrophic marker gene, a $2 \mu$ origin of replication, a GAL1 promoter, and a $C Y C 1$ terminator. Hind III was used as the cloning site between the GAL1 promoter and CYC1 terminator. AFR3 (CNAG_06909) cassette was inserted in this cloning site when transformed into S. cerevisiae AD $\Delta$ strain. The transformation was confirmed through plasmid PCR, qPCR for AFR3 expression, and sequencing of the AFR3 cassette. The figure was designed with BioRender; (B) There is no significant difference in FLC MICs between AD $\Delta$ (green line) and $\mathrm{AD} \Delta$ expressing Afr3 (AD $\Delta+$ Afr3, orange line). Error bars represent the standard deviation between biological triplicates; (C) $\mathrm{AD} \Delta+$ Afr3 (orange line) shows increased efflux when compared to AD $\Delta$ (green line). Statistical analysis was performed with multiple unpaired Student's t-test, ${ }^{* *} \mathrm{p}<0.01,{ }^{* * * *} \mathrm{p}<0.0001$. Error bars represent the standard deviation between biological triplicates; (D) AD $\Delta+$ Afr3 (orange bar) has lower Nile Red intracellular accumulation when compared to $\mathrm{AD} \Delta$ (green bar). Statistical analysis was performed with Student's t-test, ${ }^{* *} \mathrm{p}<0.01$. Error bars represent the standard deviation between biological triplicates.

\subsection{Afr3 Affects Cryptococcal Virulence}

Next, we assessed if Afr3 plays a role in virulence. First, we documented that the mutant strain exhibited no growth defect at $37^{\circ} \mathrm{C}$ when compared to the wild type (Figure S3). Next, we analyzed phagocytosis and macrophage killing of $\Delta a f r 3$ and compared the percentages to the H99 wild type. These data indicated that the phagocytosis of $\Delta a f r 3$ was comparable to that of H99. However, murine J774 macrophages more successfully killed the $\Delta a f r 3$ mutant strain after phagocytosis when compared to H99 wild-type (64\% vs. 6.6\%, p < 0.01) (Figure 4A). Last, virulence of the mutant strain was assessed in a G. mellonella infection model. The larvae infected with the $\Delta a f r 3$ strain exhibited increased survival when compared to the 
larvae infected with H99 (8 vs. 6 d median survival, $\mathrm{p}<0.0001$ ), indicating that the Afr3 pump plays a role in virulence (Figure 4B). This data is further supported by the lower number of $C$. neoformans cells circulating in the hemolymph of larvae infected with $\triangle a f r 3$ after 24 hrs when compared CFU from the hemolymph of larvae infected with H99 (29 vs. $52 \%$ cells retained, p < 0.05) (Figure 4C). These data support the notion that Afr3 is also important for C. neoformans virulence.

A

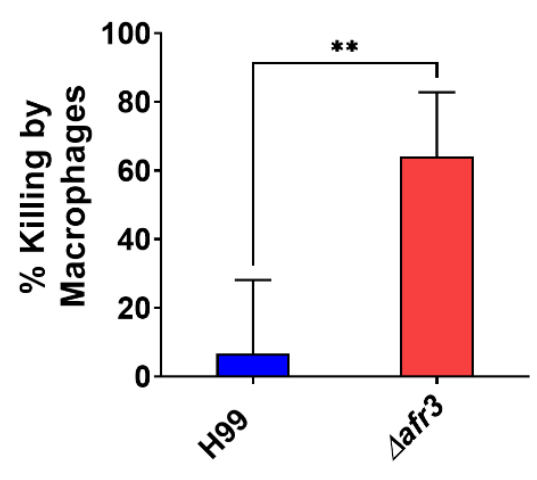

B

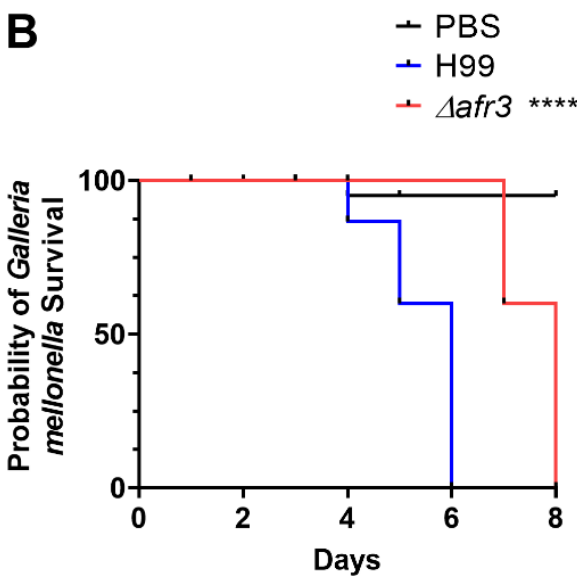

C

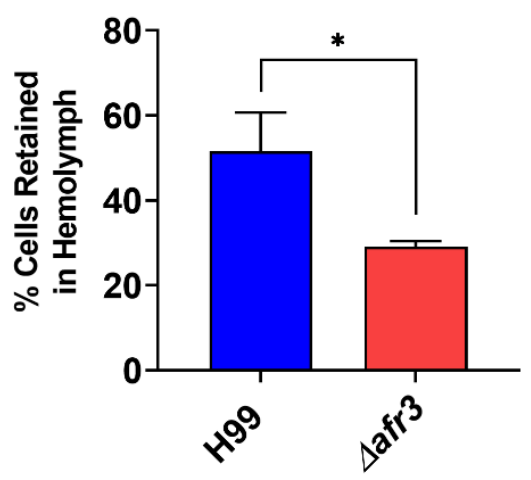

Figure 4. Afr3 Plays a Role in Virulence. (A) Phagocytosed $\triangle a f r 3$ (red bar) cells are better killed by J774A.1 murine macrophages than wild-type H99 cells (blue bar). Statistical analysis was performed with Student's t-test, ${ }^{* *} \mathrm{p}<0.01 ;(\mathbf{B})$ Galleria mellonella larvae survived longer when infected with mutant strain Aafr3 (red line) when compared to the survival of the larvae infected with wild-type H99 (blue line). Black line represents PBS uninfected controls. Statistical analysis was performed with Log-rank (Mantel-Cox) test, ${ }^{* * * *} \mathrm{p}<0.0001 ;(\mathbf{C}) \Delta a f r 3$ (red bar) has lower retention of $C$. neoformans cells in the larvae hemolymph than H99 (blue bar). Statistical analysis was performed with Student's t-test, ${ }^{*}$ p $<0.05$; Error bars signify standard deviations between the biological triplicate.

\subsection{Afr3 Affects Cryptococcal Life Span}

Given that Afr3, as well as Afr1 and Afr2, are overexpressed in 10-generation old cells, we first investigated whether Afr1, Afr2, and Afr3 affect RLS. The RLS of $\triangle a f r 3, \Delta a f r 1$, and $\Delta a f r 2$ were determined by micro-dissection and the total number of divisions the respective mutant and wild-type $C$. neoformans cells undergo before their death is recorded. These experiments showed that loss of AFR3 had a moderate prolongevity effect and extended the median RLS by $29 \%$ compared to wild-type H99 strain (22 vs. 17, p < 0.001) (Figure 5). In contrast, loss of AFR1 and AFR2 did not alter the RLS (15 and 17 median RLS, respectively). The RLS of $\triangle a f r 1$ and $\triangle \mathrm{afr} 2$ mutants exhibited high variability whereas RLS of $\triangle a f r 3$ was characterized by lower stochasticity. The coefficient of variation measures the amount of variation between individual cells within the strain data set. H99 showed $35 \%$ of variation between individual cells, while $\Delta a f r 3$ had only $14 \%$ variation, in accordance with its lower stochasticity. The mutant strains $\Delta a f r 1$ and $\Delta a f r 2$ had a much higher variation, with $55 \%$ and $65 \%$, respectively. 


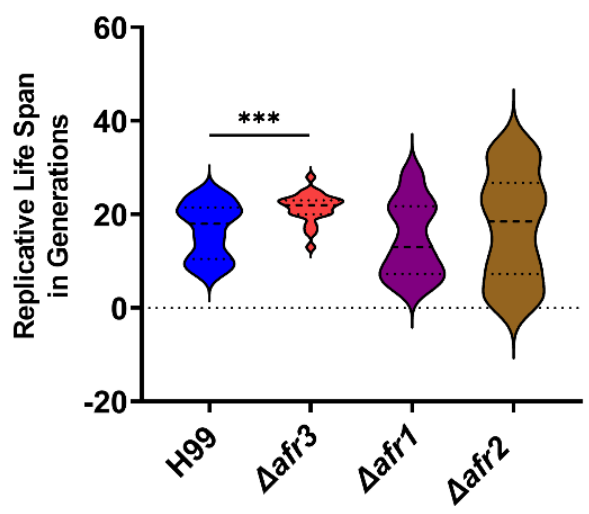

Figure 5. Afr3 Plays a Role in Aging. The C. neoformans $\triangle a f r 3$ mutant strain (red) has an expansion of the median lifespan compared to the H99 wild-type strain (blue), while $\Delta a f r 1$ (purple) and $\Delta a f r 2$ (brown) mutant strains do not show significant difference. Statistical analysis was performed with Student's t-test, ${ }^{* * *} \mathrm{p}<0.001$.

\section{Discussion}

This paper describes a novel $\mathrm{ABC}$ transporter in C. neoformans, which can efficiently efflux FLC and render C. neoformans cells more resistant to FLC. The present study was initiated because in 10-generation-old cells [15], which are more tolerant to FLC, the AFR3 gene is markedly upregulated, similarly to the upregulation of AFR1 and AFR2 genes. Based on similarities with known C. neoformans efflux pumps, Afr1 (CNAG_00730, 29.29\% identity), Afr2 (CNAG_00869, 26\% identity) and Pmr5 (CNAG_06348, 25\% identity), as well as ABC transporters from the environmental fungi, Ustilago trichophora (41.35\% identity), Lasallia pustulata (54.27\% identity), and Saitozyma podzolica (73.22\% identity), these data characterize Afr3 as member of the conserved family of ABC transporters.

Overexpression of efflux pumps, leading to decreased cellular drug concentration is a major mechanism of drug resistance [28]. During treatment of chronic cryptococcosis, this can lead to persistence of infection, despite appropriate treatment, which translates into failure to clear the fungal cells [29]. Deletion of $A F R 3$ resulted in increased sensitivity to FLC in E-Test strip analysis and increased CFU killing when higher FLC concentrations were used. However, $\triangle a$ fr3 did not exhibit differences in FLC sensitivity using the standard $\mathrm{MIC}_{80}$ assay. E-Test and microdilution methods do not always yield the same results [30], and agreement between these two tests can vary in $70-96 \%$ of the times [31]. It is conceivable that the observed difference could be due to "trailing growth", a phenomenon where fungal cells exhibit reduced but persistent growth at FLC concentrations above the MIC. This effect is more commonly observed when microdilution methods are performed [32], because in liquid assays slow growth of subpopulations may eventually dominate [33]. Interestingly, the E-Test assay indicated a lower formation of heteroresistant colonies in the $\Delta a f r 3$ mutant strain when compared to H99. Heteroresistance signifies the presence of a sub-population that manifests higher FLC tolerance when compared to the majority of the population $[34,35]$. Loss of heteroresistance was also observed with deletion of AFR1 [14]. However, the role that Afr3 plays in heterotolerance mechanisms is still to be determined.

Furthermore, the decreased Rhodamine 6G efflux, which mimics alterations in drug accumulation, corroborates the importance of Afr3 in driving drug resistance, especially since transcriptome data also suggests that there is no compensation by the other main efflux pump Afr1. Afr1 is the most well-characterized ABC transporter in C. neoformans. Deletion of AFR1 increases drug susceptibility to FLC, which is corroborated by data from a mouse infection model that indicates that Afr1 also plays a role in FLC resistance and fungal virulence $[13,34,36]$. Single deletions of Afr2 and Mdr1 did not influence susceptibility to FLC, which was only seen in a triple-deletion of Afr1, Afr2, and Mdr1 [14]. Compensatory upregulation of the transporters by qPCR in the $\triangle a f r 3$ and $\triangle a f r 1$ mutant strains 
was evaluated to assess if the lack of Afr3 would be compensated by Afr1. The data did not indicate overexpression of any transporter when the other was deleted.

Heterologous protein expression in yeast model systems, like S. cerevisiae, has enabled functional analysis of specific proteins and has been previously employed to study efflux pumps in a variety of fungi $[6,20,37]$. Although expression of AFR3 in S. cerevisiae, did not compromise viability of $S$. cerevisiae or its growth, Afr3 protein function appeared to decline rapidly within days without overt cell toxicity or loss of the plasmid. The presence of proper gene integration into the pYES2 plasmid, lack of mutations, and robust expression under the GAL1 promoter suggest that the cryptococcal Afr3 protein may not be stable in S. cerevisiae. Similar problems have been encountered with other heterologous proteins, which were found to be unstable in S. cerevisiae [38-41]. This may explain the lack of difference in the FLC MIC between AD $\Delta$ and AD $\Delta+$ Afr3, as it requires several days of incubation. The Rhodamine 6G and Nile Red experiments, however, clearly demonstrated the increase of efflux when Afr3 was expressed. In contrast to MIC experiments, these experiments were done on the same day the transformants were recovered.

Moreover, since both drug resistance and heteroresistance have been linked to increased virulence [34], the decreased cryptococcal virulence of $\Delta a f r 3$ in a Galleria mellonella survival model further confirms the important role of this efflux pump. The efflux pumps may play a role not only in the decrease of FLC concentration but also in detoxification of the cell by extruding metabolites and other components that may be detrimental [42]. Accumulation of toxic metabolites can lead to loss of cell fitness and impact fungal virulence. Other fungal pumps have been shown to impact virulence, including Atm1, a mitochondrial ABC pump in C. neoformans, Mlt1, a vacuolar ABC transporter in Candida albicans, and $\mathrm{AbcB}$, an efflux pump of Aspergillus fumigatus [43-45]. As efflux pumps can aid in the process of detoxification of the cell, we anticipated a decrease in RLS in the $\Delta a f r 3$ as have been described for other efflux pumps in S. cerevisiae [17]. Instead, we documented a moderate increase in RLS of the $\triangle \mathrm{afr} 3$ strain was also associated with a loss of variability of lifespan which may indicate a specific role in stress response, while the $\Delta a f r 1$ and $\Delta a f r 2$ mutants maintained high stochasticity, similar to the wild-type strain. Stochasticity of life span is still poorly understood in C. neoformans.

Exposure to stress, such as glucose deprivation, leads to an increase in FLC tolerance, as the change is only transient and does not become intrinsic to the strain [46]. Low glucose conditions lead to an increase in efflux through increased pump activity dependent on Afr1 [46]. Thus, we explored whether Afr3 contributes to increased FLC tolerance under low glucose growth conditions. We found AFR3 deletion did not affect the enhanced FLC tolerance under glucose starvation, nor did we observe upregulation of AFR3 during glucose deprivation. C. neoformans can achieve resistance to FLC by the duplication of chromosome 1 and rarely chromosome 3 in response to prolonged exposure to FLC. Chromosome 1 is most commonly duplicated, increasing the copy number of genes ERG11 and AFR1 [47]. The observed increased FLC tolerance in low glucose growth conditions, however, is not associated with a change in gene copy number of AFR1 or AFR2. [46]. AFR3 is located on chromosome 3 and the gene copy number was unchanged under low glucose stress (data not shown). It was previously hypothesized that the increase in efflux pump expression is being driven by stress-induced upregulation of transcription factors, as many transcription factors correlated with FLC resistance are upregulated in low glucose $[14,46,48]$. Afr3, as well as the other characterized ABC transporters (Afr1, Afr2, and Mdr1), are upregulated in 10-generations old cells. Additionally, the results from the modified killing assay showed that deletion of AFR3 in older cells leads to a partial loss of resistance, indicating that Afr3 could aid in the FLC tolerance observed in 10-generation cells.

In summary, these data identify a novel ABC transporter that contributes to FLC tolerance in C. neoformans older cells. This ABC transporter promotes drug efflux from the fungal cell, influencing the susceptibility to treatment and the virulence of the cryptococcal cells. Our data encourage further efforts to understand its role in relation to other efflux pumps and which mechanisms the aging cells employ to increase drug resistance. 
Supplementary Materials: The following are available online at www.mdpi.com/xxx/s1; Figure S1: Confirmation of Saccharomyces cerevisiae Transformants; Figure S2: Pump Compensation between Afr1 and Afr3; Figure S3: Growth Curves; Table S1: List of Primers.

Author Contributions: NKO and SB contributed significantly to the study design. NKO, SB, RG, and $\mathrm{MJ}$ performed the experiments. $\mathrm{NKO}, \mathrm{SB}$, and $\mathrm{BF}$ wrote the article. All authors have read and agreed to the published version of the manuscript.

Funding: This research was funded by the National Institutes of Health (NIH 1R01AI127704- 01A1 to B.C.F.).

Acknowledgments: We thank the Fries Lab for their input in this manuscript. We also thank Dr. Theodore C. White at the University of Missouri, Kansas City for gifting us the Saccharomyces cerevisiae strain AD $\Delta$ and the pYES2 plasmid, and Dr. Kwon-Chung for the $\Delta a f r 1$ and $\Delta a f r 2$ mutant strains. We thank BioRender for supplying the software used to design Figure 4A, and we thank Barbara Marques for her contribution in developing Figure 1B.

Conflicts of Interest: The authors declare no conflict of interest.

\section{References}

1. Rajasingham, R.; Smith, R.M.; Park, B.J.; Jarvis, J.N.; Govender, N.P.; Chiller, T.M.; Denning, D.W.; Loyse, A.; Boulware, D.R. Global burden of disease of HIV-associated cryptococcal meningitis: an updated analysis. Lancet Infect Dis 2017, 17, 873-881, doi:10.1016/S1473-3099(17)30243-8.

2. $\quad$ Perfect, J.R.; Dismukes, W.E.; Dromer, F.; Goldman, D.L.; Graybill, J.R.; Hamill, R.J.; Harrison, T.S.; Larsen, R.A.; Lortholary, O.; Nguyen, M.H.; et al. Clinical practice guidelines for the management of cryptococcal disease: 2010 update by the infectious diseases society of america. Clin Infect Dis 2010, 50, 291-322, doi:10.1086/649858.

3. Hope, W.; Stone, N.R.H.; Johnson, A.; McEntee, L.; Farrington, N.; Santoro-Castelazo, A.; Liu, X.; Lucaci, A.; Hughes, M.; Oliver, J.D.; et al. Fluconazole Monotherapy Is a Suboptimal Option for Initial Treatment of Cryptococcal Meningitis Because of Emergence of Resistance. mBio 2019, 10, doi:10.1128/mBio.02575-19.

4. Longley, N.; Muzoora, C.; Taseera, K.; Mwesigye, J.; Rwebembera, J.; Chakera, A.; Wall, E.; Andia, I.; Jaffar, S.; Harrison, T.S. Dose response effect of high-dose fluconazole for HIV-associated cryptococcal meningitis in southwestern Uganda. Clin Infect Dis 2008, 47, 1556-1561, doi:10.1086/593194.

5. Rothe, C.; Sloan, D.J.; Goodson, P.; Chikafa, J.; Mukaka, M.; Denis, B.; Harrison, T.; van Oosterhout, J.J.; Heyderman, R.S.; Lalloo, D.G.; et al. A prospective longitudinal study of the clinical outcomes from cryptococcal meningitis following treatment induction with $800 \mathrm{mg}$ oral fluconazole in Blantyre, Malawi. PLoS One 2013, 8, e67311, doi:10.1371/journal.pone.0067311.

6. Cannon, R.D.; Lamping, E.; Holmes, A.R.; Niimi, K.; Baret, P.V.; Keniya, M.V.; Tanabe, K.; Niimi, M.; Goffeau, A.; Monk, B.C. Efflux-mediated antifungal drug resistance. Clin Microbiol Rev 2009, 22, 291-321, Table of Contents, doi:10.1128/CMR.00051-08.

7. Bhattacharya, S.; Esquivel, B.D.; White, T.C. Overexpression or Deletion of Ergosterol Biosynthesis Genes Alters Doubling Time, Response to Stress Agents, and Drug Susceptibility in Saccharomyces cerevisiae. mBio 2018, 9 , doi:10.1128/mBio.01291-18.

8. Selmecki, A.; Gerami-Nejad, M.; Paulson, C.; Forche, A.; Berman, J. An isochromosome confers drug resistance in vivo by amplification of two genes, ERG11 and TAC1. Mol Microbiol 2008, 68, 624-641, doi:10.1111/j.1365-2958.2008.06176.x.

9. Sanglard, D.; Ischer, F.; Koymans, L.; Bille, J. Amino acid substitutions in the cytochrome P-450 lanosterol 14alphademethylase (CYP51A1) from azole-resistant Candida albicans clinical isolates contribute to resistance to azole antifungal agents. Antimicrob Agents Chemother 1998, 42, 241-253, doi:10.1128/AAC.42.2.241. 
10. Sheng, C.; Miao, Z.; Ji, H.; Yao, J.; Wang, W.; Che, X.; Dong, G.; Lu, J.; Guo, W.; Zhang, W. Three-dimensional model of lanosterol 14 alpha-demethylase from Cryptococcus neoformans: active-site characterization and insights into azole binding. Antimicrob Agents Chemother 2009, 53, 3487-3495, doi:10.1128/AAC.01630-08.

11. Basso, L.R., Jr.; Gast, C.E.; Bruzual, I.; Wong, B. Identification and properties of plasma membrane azole efflux pumps from the pathogenic fungi Cryptococcus gattii and Cryptococcus neoformans. J Antimicrob Chemother 2015, 70, 1396-1407, doi:10.1093/jac/dku554.

12. Del Sorbo, G.; Schoonbeek, H.; De Waard, M.A. Fungal transporters involved in efflux of natural toxic compounds and fungicides. Fungal Genet Biol 2000, 30, 1-15, doi:10.1006/fgbi.2000.1206.

13. Sanguinetti, M.; Posteraro, B.; La Sorda, M.; Torelli, R.; Fiori, B.; Santangelo, R.; Delogu, G.; Fadda, G. Role of AFR1, an $\mathrm{ABC}$ transporter-encoding gene, in the in vivo response to fluconazole and virulence of Cryptococcus neoformans. Infect Immun 2006, 74, 1352-1359, doi:10.1128/IAI.74.2.1352-1359.2006.

14. Chang, M.; Sionov, E.; Khanal Lamichhane, A.; Kwon-Chung, K.J.; Chang, Y.C. Roles of Three Cryptococcus neoformans and Cryptococcus gattii Efflux Pump-Coding Genes in Response to Drug Treatment. Antimicrob Agents Chemother 2018, 62, doi:10.1128/AAC.01751-17.

15. Orner, E.P.; Zhang, P.; Jo, M.C.; Bhattacharya, S.; Qin, L.; Fries, B.C. High-Throughput Yeast Aging Analysis for Cryptococcus (HYAAC) microfluidic device streamlines aging studies in Cryptococcus neoformans. Commun Biol 2019, 2, 256, doi:10.1038/s42003-019-0504-5.

16. Bhattacharya, S.; Bouklas, T.; Fries, B.C. Replicative Aging in Pathogenic Fungi. J Fungi (Basel) 2020, 7 , doi:10.3390/jof7010006.

17. Eldakak, A.; Rancati, G.; Rubinstein, B.; Paul, P.; Conaway, V.; Li, R. Asymmetrically inherited multidrug resistance transporters are recessive determinants in cellular replicative ageing. Nat Cell Biol 2010, 12, 799-805, doi:10.1038/ncb2085.

18. Orner, E.P.; Bhattacharya, S.; Kalenja, K.; Hayden, D.; Del Poeta, M.; Fries, B.C. Cell Wall-Associated Virulence Factors Contribute to Increased Resilience of Old Cryptococcus neoformans Cells. Front Microbiol 2019, 10, 2513, doi:10.3389/fmicb.2019.02513.

19. Jain, N.; Cook, E.; Xess, I.; Hasan, F.; Fries, D.; Fries, B.C. Isolation and characterization of senescent Cryptococcus neoformans and implications for phenotypic switching and pathogenesis in chronic cryptococcosis. Eukaryot Cell 2009, 8, 858-866, doi:10.1128/EC.00017-09.

20. Lamping, E.; Monk, B.C.; Niimi, K.; Holmes, A.R.; Tsao, S.; Tanabe, K.; Niimi, M.; Uehara, Y.; Cannon, R.D. Characterization of three classes of membrane proteins involved in fungal azole resistance by functional hyperexpression in Saccharomyces cerevisiae. Eukaryot Cell 2007, 6, 1150-1165, doi:10.1128/EC.00091-07.

21. Gietz, R.D.; Woods, R.A. Transformation of yeast by lithium acetate/single-stranded carrier DNA/polyethylene glycol method. Methods Enzymol 2002, 350, 87-96, doi:10.1016/s0076-6879(02)50957-5.

22. Bouklas, T.; Pechuan, X.; Goldman, D.L.; Edelman, B.; Bergman, A.; Fries, B.C. Old Cryptococcus neoformans cells contribute to virulence in chronic cryptococcosis. mBio 2013, 4, doi:10.1128/mBio.00455-13.

23. Cuenca-Estrella, M.; Lee-Yang, W.; Ciblak, M.A.; Arthington-Skaggs, B.A.; Mellado, E.; Warnock, D.W.; RodriguezTudela, J.L. Comparative evaluation of NCCLS M27-A and EUCAST broth microdilution procedures for antifungal susceptibility testing of candida species. Antimicrob Agents Chemother 2002, 46, 3644-3647, doi:10.1128/AAC.46.11.36443647.2002 .

24. Bouklas, T.; Jain, N.; Fries, B.C. Modulation of Replicative Lifespan in Cryptococcus neoformans: Implications for Virulence. Front Microbiol 2017, 8, 98, doi:10.3389/fmicb.2017.00098.

25. Bhattacharya, S.; Sobel, J.D.; White, T.C. A Combination Fluorescence Assay Demonstrates Increased Efflux Pump Activity as a Resistance Mechanism in Azole-Resistant Vaginal Candida albicans Isolates. Antimicrob Agents Chemother 2016, 60, 5858-5866, doi:10.1128/AAC.01252-16. 
26. Bouklas, T.; Diago-Navarro, E.; Wang, X.; Fenster, M.; Fries, B.C. Characterization of the virulence of Cryptococcus neoformans strains in an insect model. Virulence 2015, 6, 809-813, doi:10.1080/21505594.2015.1086868.

27. Livak, K.J.; Schmittgen, T.D. Analysis of relative gene expression data using real-time quantitative PCR and the 2(-Delta Delta C(T)) Method. Methods 2001, 25, 402-408, doi:10.1006/meth.2001.1262.

28. Shapiro, R.S.; Robbins, N.; Cowen, L.E. Regulatory circuitry governing fungal development, drug resistance, and disease. Microbiol Mol Biol Rev 2011, 75, 213-267, doi:10.1128/MMBR.00045-10.

29. White, T.C.; Marr, K.A.; Bowden, R.A. Clinical, cellular, and molecular factors that contribute to antifungal drug resistance. Clin Microbiol Rev 1998, 11, 382-402, doi:10.1128/CMR.11.2.382.

30. Dannaoui, E.; Paugam, A.; Develoux, M.; Chochillon, C.; Matheron, J.; Datry, A.; Bouges-Michel, C.; Bonnal, C.; Dromer, F.; Bretagne, S. Comparison of antifungal MICs for yeasts obtained using the EUCAST method in a reference laboratory and the Etest in nine different hospital laboratories. Clin Microbiol Infect 2010, 16, 863-869, doi:10.1111/j.14690691.2009.02997.x.

31. Aller, A.I.; Martin-Mazuelos, E.; Gutierrez, M.J.; Bernal, S.; Chavez, M.; Recio, F.J. Comparison of the Etest and microdilution method for antifungal susceptibility testing of Cryptococcus neoformans to four antifungal agents. J Antimicrob Chemother 2000, 46, 997-1000, doi:10.1093/jac/46.6.997.

32. Marcos-Zambrano, L.J.; Escribano, P.; Sanchez-Carrillo, C.; Bouza, E.; Guinea, J. Scope and frequency of fluconazole trailing assessed using EUCAST in invasive Candida spp. isolates. Med Mycol 2016, 54, 733-739, doi:10.1093/mmy/myw033.

33. Berman, J.; Krysan, D.J. Drug resistance and tolerance in fungi. Nat Rev Microbiol 2020, 18, 319-331, doi:10.1038/s41579-0190322-2.

34. Sionov, E.; Chang, Y.C.; Garraffo, H.M.; Kwon-Chung, K.J. Heteroresistance to fluconazole in Cryptococcus neoformans is intrinsic and associated with virulence. Antimicrob Agents Chemother 2009, 53, 2804-2815, doi:10.1128/AAC.00295-09.

35. Mondon, P.; Petter, R.; Amalfitano, G.; Luzzati, R.; Concia, E.; Polacheck, I.; Kwon-Chung, K.J. Heteroresistance to fluconazole and voriconazole in Cryptococcus neoformans. Antimicrob Agents Chemother 1999, 43, 1856-1861, doi:10.1128/AAC.43.8.1856.

36. Posteraro, B.; Sanguinetti, M.; Sanglard, D.; La Sorda, M.; Boccia, S.; Romano, L.; Morace, G.; Fadda, G. Identification and characterization of a Cryptococcus neoformans ATP binding cassette (ABC) transporter-encoding gene, CnAFR1, involved in the resistance to fluconazole. Mol Microbiol 2003, 47, 357-371, doi:10.1046/j.1365-2958.2003.03281.x.

37. Gauthier, C.; Weber, S.; Alarco, A.M.; Alqawi, O.; Daoud, R.; Georges, E.; Raymond, M. Functional similarities and differences between Candida albicans Cdr1p and Cdr2p transporters. Antimicrob Agents Chemother 2003, 47, 1543-1554, doi:10.1128/AAC.47.5.1543-1554.2003.

38. Parekh, R.N.; Wittrup, K.D. Expression level tuning for optimal heterologous protein secretion in Saccharomyces cerevisiae. Biotechnol Prog 1997, 13, 117-122, doi:10.1021/bp970009d.

39. Vazquez, E.; Corchero, J.L.; Villaverde, A. Post-production protein stability: trouble beyond the cell factory. Microb Cell Fact 2011, 10, 60, doi:10.1186/1475-2859-10-60.

40. Kingsman, S.M.; Kingsman, A.J.; Dobson, M.J.; Mellor, J.; Roberts, N.A. Heterologous gene expression in Saccharomyces cerevisiae. Biotechnol Genet Eng Rev 1985, 3, 377-416, doi:10.1080/02648725.1985.10647819.

41. Stepien, P.P.; Brousseau, R.; Wu, R.; Narang, S.; Thomas, D.Y. Synthesis of a human insulin gene. VI. Expression of the synthetic proinsulin gene in yeast. Gene 1983, 24, 289-297, doi:10.1016/0378-1119(83)90089-6.

42. Ernst, R.; Klemm, R.; Schmitt, L.; Kuchler, K. Yeast ATP-binding cassette transporters: cellular cleaning pumps. Methods Enzymol 2005, 400, 460-484, doi:10.1016/S0076-6879(05)00026-1. 
43. Do, E.; Park, S.; Li, M.H.; Wang, J.M.; Ding, C.; Kronstad, J.W.; Jung, W.H. The mitochondrial ABC transporter Atm1 plays a role in iron metabolism and virulence in the human fungal pathogen Cryptococcus neoformans. Med Mycol 2018, 56, 458468, doi:10.1093/mmy/myx073.

44. Paul, S.; Diekema, D.; Moye-Rowley, W.S. Contributions of Aspergillus fumigatus ATP-binding cassette transporter proteins to drug resistance and virulence. Eukaryot Cell 2013, 12, 1619-1628, doi:10.1128/EC.00171-13.

45. Theiss, S.; Kretschmar, M.; Nichterlein, T.; Hof, H.; Agabian, N.; Hacker, J.; Kohler, G.A. Functional analysis of a vacuolar $\mathrm{ABC}$ transporter in wild-type Candida albicans reveals its involvement in virulence. Mol Microbiol 2002, 43, 571-584, doi:10.1046/j.1365-2958.2002.02769.x.

46. Bhattacharya, S.; Oliveira, N.K.; Savitt, A.G.; Silva, V.K.A.; Krausert, R.B.; Ghebrehiwet, B.; Fries, B.C. Low Glucose Mediated Fluconazole Tolerance in Cryptococcus neoformans. J Fungi (Basel) 2021, 7, doi:10.3390/jof7060489.

47. Sionov, E.; Lee, H.; Chang, Y.C.; Kwon-Chung, K.J. Cryptococcus neoformans overcomes stress of azole drugs by formation of disomy in specific multiple chromosomes. PLoS Pathog 2010, 6, e1000848, doi:10.1371/journal.ppat.1000848.

48. Jung, K.W.; Yang, D.H.; Maeng, S.; Lee, K.T.; So, Y.S.; Hong, J.; Choi, J.; Byun, H.J.; Kim, H.; Bang, S.; et al. Systematic functional profiling of transcription factor networks in Cryptococcus neoformans. Nat Commun 2015, 6, 6757, doi:10.1038/ncomms7757. 